\title{
Fecal DNA screening in colorectal cancer
}

\author{
Suzanne Richter MD MSc
}

S Richter. Fecal DNA screening in colorectal cancer. Can J Gastroenterol 2008;22(7):631-633.

Colorectal cancer (CRC) is the third most common type of cancer diagnosed in Canada, and is the leading cause of cancer-related deaths in nonsmokers. Although CRC is considered to be $90 \%$ curable if detected early, the majority of patients present with advanced stage III or IV disease. An effective screening test may significantly decrease disease burden. The present paper examines the rationale and potential of fecal DNA testing as an alternative and adjunct to other CRC screening tests. The most efficacious fecal DNA test developed to date has a sensitivity and specificity of $87.5 \%$ and $82 \%$, respectively. The approach has a higher positive predictive value than the currently used fecal occult blood test and offers a noninvasive option to patients. It is not reliant on the presence of bleeding, which may be intermittent or altogether absent. The test is now commercially available and is supported by a number of American insurers. Current challenges include cost reduction and demonstration of mortality benefit in a rigorous clinical trial. Despite current challenges, fecal DNA testing is worth pursuing. Both the American Gastroenterological Society and the American Cancer Society maintain that molecular testing is in its infancy but is promising. Fecal DNA testing has the potential to be an exciting addition to the current armament of CRC screening options.

Key Words: Colonoscopy; Colorectal cancer; DNA testing; FOBT

\section{L'analyse de l'ADN fécal en cas de cancer colorectal}

Le cancer colorectal (CCR) est la troisième forme de cancer en importance à être diagnostiquée au Canada, et c'est la principale cause de décès par cancer chez les non-fumeurs. Bien qu'on considère que le CCR peut être guéri dans $90 \%$ des cas s'il est dépisté assez tôt, la majorité des patients consultent lorsque la maladie est de stade III ou IV. Un test de dépistage efficace pourrait réduire considérablement le fardeau de la maladie. Le présent article analyse la justification et le potentiel du test d'ADN fécal pour remplacer ou compléter d'autres tests de dépistage du CCR. Le test d'ADN fécal le plus efficace jusqu'à présent a une sensibilité et une spécificité de $87,5 \%$ et de $82 \%$, respectivement. La démarche a une valeur prédictive positive supérieure au test de sang occulte fécal actuel et constitue une solution non effractive pour les patients. Elle ne dépend pas de la présence de sang, qui peut être intermittente ou inexistante. Le test est maintenant en marché et remboursé par plusieurs grands assureurs américains. Les problèmes courants incluent la réduction des coûts et la démonstration de la diminution des décès dans le cadre d'un essai clinique rigoureux. Malgré les problèmes courants, le test d'ADN fécal mérite d'être utilisé. Tant l'American Gastroenterological Society que l'American Cancer Society affirment que les tests moléculaires sont prometteurs même s'ils sont à leurs balbutiements. Le test d'ADN fécal a le potentiel de constituer un ajout intéressant aux possibilités de dépistage du CCR.

\section{COLORECTAL CANCER SCREENING}

Colorectal cancer (CRC) is the third most common cancer diagnosed in Canada and the leading cause of cancer-related deaths in nonsmokers. More than 20,000 new cases were expected in Canada for 2007, and of these, approximately $40 \%$ of patients were estimated to die from the disease (1). Although CRC is considered to be $90 \%$ curable if detected early, the majority of patients present with advanced stage III or IV disease (2). Many of these patients have never undergone regular CRC screening.

Current screening guidelines in Canada that recommend fecal occult blood testing (FOBT) are based on randomized, controlled trials showing a $7 \%$ to $33 \%$ reduction in mortality (3-6). Data from similar trials assessing the use of either colonoscopy or computed tomography colonoscopy to reduce mortality are currently unavailable. The benefits of FOBT include feasibility, economics and evidence. The disadvantages include reduced positive predictive value, clinical yield (number needed to treat is 1173 over 10 years of follow-up), and the cost and risk associated with negative invasive investigation.

$\mathrm{CRC}$ is highly suited to population screening. It is highly prevalent and progresses through a long premalignant phase. Early detection allows for more effective treatment. An effective alternative to FOBT might reduce the burden of disease.
Several recent advances, including the sequencing of the human genome and the development of high-throughput molecular techniques have accelerated cancer research. Fecal DNA testing is currently being developed as an alternative to other CRC screening techniques. The approach has improved sensitivity over FOBT and offers a noninvasive option to patients. The test is now available and is gaining attention.

\section{CANCER GENETICS}

A cancer cell develops through a collection of gene mutations. Mutations left uncorrected by cell cycle regulation before division are fixed in that cell and in its future progenitors. A cell undergoes full carcinogenic transformation once a sufficient number of genes are mutated and the cell can no longer respond to the external signals that act as brakes on cell growth.

The most common genetic screening test detects the BRCA gene for hereditary breast cancer (7). The test identifies susceptibility, because the BRCA mutation is an early change required for disease development. The test cannot differentiate between susceptibility (early preclinical disease) and fully developed disease because, although BRCA mutation is necessary to initiate disease development, numerous other genes must also be affected before breast cancer can progress to disease that is clinically relevant. For this reason, 
BRCA testing is considered to be a preclinical screening test that is capable of identifying individuals at risk for inherited breast cancer in the future. Patients at risk for inherited breast cancer have a mutated BRCA gene in all of their cells at birth, including blood cells. The simplicity of the test lies in the fact that a simple blood test for a single gene can detect susceptibility.

Genetic testing in CRC differs from BRCA screening for two reasons (8). First, rather than being inherited, the majority of CRC cases are sporadic. This means that mutated genes are present only in precancerous and cancerous lesions in the colon and rectum, and are not present in all cells of the body. Therefore, CRC cannot be detected by a blood test. Second, there is no single gene required for disease initiation. Rather, there are seven to 10 genes responsible for neoplastic transformation (9). Therefore, population-based genetic screening for $\mathrm{CRC}$ is a more laborious task than presymptomatic screening for hereditary breast cancer.

Fearon and Vogelstein (9) outlined the genetic changes in tissues at different morphological stages, ranging from premalignant adenoma to CRC carcinoma and metastasis. Approximately seven to 10 mutations occur over a 10 -year period. The genes are tumour suppressor genes (ie, suppress the cell cycle until inactivated by a mutation) and oncogenes (ie, allow for uncontrolled cell growth when activated by a mutation). Other genes and genetic changes recently identified as contributing to the adenoma-carcinoma sequence include promoter methylation (gene silencing) and microsatellite instability (susceptibility of repeat sequences to replication error and mutation). Recently, markers of apoptosis have also been identified (10). Different genetic and gene types are relevant to genetic testing because each change requires different molecular methodology for detection. The specific changes chosen for test analysis will also have an impact on test sensitivity and specificity.

\section{FROM BENCH TO BEDSIDE}

Cells from the colonic mucosa slough, and are found in the bowel lumen and stool. Cells from tumours and adenomas are particularly abundant because they are less susceptible to apoptosis and grow more rapidly than their normal counterparts.

Stool-based DNA screening requires the patient to collect a single whole stool sample. There are no dietary restrictions, cathartics or sample manipulations required.

Patient DNA is harvested from the colon cells extracted from the stool. The DNA is then accurately replicated by the polymerase chain reaction (PCR) to provide sufficient material for analysis. Bacterial DNA does not contaminate the replication because it does not contain the human sequences recognized in the PCR reactions. The amplified DNA is subsequently analyzed for the genetic alterations associated with cancer and precancerous changes using PCR-based methodologies. If a DNA abnormality is identified, colonoscopy follows.

\section{STOOL DNA SCREENING PERFORMANCE}

FOBT specificity and sensitivity are $95 \%$ and $15 \%$ to $30 \%$, respectively. The low positive predictive value of FOBT indicates that as many as $80 \%$ of patients proceed to negative colonoscopy (11), exposing them to risks.

The published experience with fecal DNA testing suggests an aggregate sensitivity of $65 \%$ (95\% CI $57 \%$ to $71 \%$ ) $(10,12-16)$. In the first large-scale test sponsored by the developing company (EXACT Sciences Corporation, USA), fecal DNA screening tested favourably over the traditional Hemoccult II test (Beckman Coulter, Inc, USA) in a superiority trial. Imperiale et al (12) tested a population of asymptomatic individuals aged 50 to 75 years with average risk for CRC. The sensitivity and specificity of fecal DNA testing for CRC were $52 \%$ and $94 \%$, respectively. DNA testing was shown to be four times as effective at identifying invasive cancer and twice as effective at detecting adenomas with highgrade dysplasia than a single Hemoccult II sample. The results were encouraging, but the use of the one-sample, as opposed to the six-sample, Hemoccult II test as a control may have overestimated the superiority of the fecal DNA test.

A number of factors can contribute to the sensitivity and specificity of a genetic screening test. These include DNA quality, molecular technology and the specific genetic changes chosen for analysis. The initial test developed by Imperiale et al (12) analyzed 22 gene mutations and measured apoptosis indirectly by the presence of long pieces of DNA. This approach was recently reworked and published in the January 2007 edition of Clinical Gastroenterology and Hepatology (10). The group evaluated 162 patients - 40 individuals with cancer and 122 individuals with normal colonoscopy results. Their tests yielded a sensitivity of $87.5 \%$ and a specificity of $82 \%$, which are the highest values reported to date. The improved efficacy was largely accounted for by new technology, which included a measure of gene methylation. The sensitivity was also heightened by improving the test substrate. A DNA stabilizing fixative was added to the stool, which better preserved the genetic alterations being tested. Direct mutation detection used in the previous test was found to be of little benefit to sensitivity. The implication was a simpler, less expensive test more amenable to widespread use.

Other approaches have been tried but have not matched the success of fecal DNA testing. Kanaoka et al (13) evaluated cyclooxygenase-2 (COX-2) and carcinoembryonic antigen overexpression in fecal RNA. In a pilot study including 29 CRC patients and 22 patients without neoplastic disease, COX-2 messenger RNA levels were 90\% sensitive and 100\% specific for the disease. Carcinoembryonic antigen specificity was too low to be considered as a marker. A larger study is necessary to confirm the accuracy and efficacy of the COX-2 RNA test, but RNA-based molecular testing may not be feasible outside the rigorous setting of a laboratory study because of its significant molecular instability compared with DNA.

\section{COST ANALYSIS}

The cost of the genetic test is US\$495. FOBT is merely US\$75. Cost alone is insufficient for full evaluation, and the additional cost of follow-up colonoscopies and the impact on mortality needs to be considered. Wu et al (14) analyzed the cost-effectiveness of fecal DNA testing in countries with intermediate incidence. They compared DNA testing with annual FOBT, flexible sigmoidoscopy every five years and colonoscopy every 10 years. They found that stool DNA testing strategies were the least effective with respect to cost per test, referral rates and the prevalence of large adenomas.

A complementary result was found by Song et al (15), who assessed the cost-effectiveness of Imperiale's screening test through Markov modelling. Using a sensitivity of $40 \%$ for adenomas and $60 \%$ for carcinomas and a test cost of US\$695, the cost was US $\$ 47,700$ per incremental life year gained. The 
group calculated that the test cost would need to be reduced to US\$195 to be effective, assuming a sensitivity 10\% higher than that published in the trial by Imperiale et al.

Currently, cost efficiency is a barrier to fecal DNA testing. However, it is noted that the analysis by Song et al was performed using the results of Imperiale's earlier trial, which used a more expensive and labour-intensive test. In addition, cost analyses to date have not accounted for those patients who, secondary to their fear and avoidance of colonoscopic investigation, present with late-stage disease requiring expensive chemotherapy at a significant cost to the health care system. Fecal DNA testing may equate to cost savings through improved compliance.

\section{SUMMARY}

Presymptomatic screening for CRC and its precursors may enable earlier intervention and improved health outcomes. The ideal screening test should be safe, highly sensitive and specific, cost-efficient, and acceptable to the public. Current guidelines support annual or biennial FOBT screening.

Fecal DNA testing offers multiple advantages as a screening tool (Table 1). It is a noninvasive test with a sensitivity approaching $90 \%$ and a specificity of $82 \%$ (for the most accurate test to date). It has increased positive predictive value over other noninvasive tests and can also be used in conjunction with colonoscopy. Because it detects molecular changes occurring over a seven- to 10 -year period, the long premalignant time offers earlier detection and improved outcomes. DNA testing is not reliant on the presence of bleeding, which may be intermittent or altogether absent.

The challenges of cost and limited sensitivity remain. Although approximately six times the cost of FOBT, the
TABLE 1

Efficacy and cost comparison for colorectal cancer screening alternatives

\begin{tabular}{lccc}
\hline Test (reference) & Sensitivity, \% & Specificity, \% & Cost (US\$) \\
\hline FOBT (4-6) & $15-30$ & 95 & 75.00 \\
Colonoscopy (17) & $>90$ & $>99$ & 606.00 \\
Fecal DNA test, version 1 (10) & 51.6 & 95.2 & 495.00 \\
Fecal DNA test, version 2 (10) & 87.5 & 82 & N/A \\
\hline
\end{tabular}

FOBT Fecal occult blood test; N/A Not applicable

molecular strategy is expected to become more affordable and accessible with time. Sensitivity is limited because no one single genetic change is universal, and the full range of genetic changes in CRC remains to be elucidated. Although the model of adenoma-carcinoma and other genetic changes have been identified, ongoing work suggests that there are still more changes driving this process and that in some lesions, expected changes may be absent. K-ras mutations, for example, are absent in certain types of adenomas (16).

Despite current challenges, fecal DNA testing is worth pursuing. Although there are no published trials directly comparing fecal DNA screening with FOBT or colonoscopy, the first-generation DNA test is available in the United States and is covered by some American insurers. Both the American Gastroenterological Society and the American Cancer Society maintain that molecular testing is still young but carries promise. Ongoing scientific work in this area may lead to the identification of new diagnostic markers, prognostic indicators and chemotherapeutic agents.

\section{REFERENCES}

1. Canadian Cancer Society/National Cancer Institute of Canada. Canadian Cancer Statistics 2007. Toronto, Canada, 2007.

2. Jemal A, Murray T, Ward E, et al. Cancer statistics, 2005. CA Cancer J Clin 2005;55:10-30. (Erratum in 2005;55:259).

3. McLeod R; Canadian Task Force on Preventive Health Care. Screening strategies for colorectal cancer: Systematic review \& recommendations. CTFPHC Technical Report \#01-2. London: Canadian Task Force of Preventive Health Care, 2001.

4. Kronborg O, Fenger C, Olsen J, Jorgensen OD, Sondergaard O. Randomised study of screening for colorectal cancer with faecal-occult-blood test. Lancet 1996;348:1467-71.

5. Hardcastle JD, Chamberlain JO, Robinson MH, et al. Randomised controlled trial of faecal-occult-blood screening for colorectal cancer. Lancet 1996;348:1472-7.

6. Mandel JS, Bond JH, Church TR, et al. Reducing mortality from colorectal cancer by screening for fecal occult blood. Minnesota Colon Cancer Control Study. N Engl J Med 1993;328:1365-71. (Erratum in 1993;328:1365-71).

7. Hall MJ, Olopade OI. Disparities in genetic testing: Thinking outside the BRCA box. J Clin Oncol 2006;24:2197-203.

8. Calvert PM, Frucht H. The genetics of colorectal cancer. Ann Intern Med 2002;137:603-12.

9. Fearon ER, Vogelstein B. A genetic model for colorectal tumorigenesis. Cell 1990;61:759-67.

10. Itzkowitz SH, Jandorf L, Brand R, et al. Improved fecal DNA test for colorectal cancer screening. Clin Gastroenterol Hepatol 2007;5:111-7.

11. Towler B, Irwig L, Glasziou P, Kewenter J, Weller D, Silagy C. A systematic review of the effects of screening for colorectal cancer using the fecal occult blood test, hemoccult. BMJ 1998;317:559-65.

12. Imperiale TF, Ransohoff DF, Itzkowitz SH, Turnbull BA, Ross ME; Colorectal Cancer Study Group. Fecal DNA versus fecal occult blood for colorectal-cancer screening in an average-risk population. N Engl J Med 2004;351:2704-14.

13. Kanaoka S, Yoshida K, Miura N, Sugimura H, Kajimura M. Potential usefulness of detecting cyclooxygenase 2 messenger RNA in feces for colorectal cancer screening. Gastroenterology 2004;127:422-7.

14. Wu G, Wang YM, Yen AM, et al. Cost-effectiveness analysis of colorectal cancer screening with stool DNA testing in intermediate-incidence countries. BMC Cancer 2006;6:136.

15. Song K, Fendrick AM, Ladabaum U. Fecal DNA testing compared with conventional colorectal cancer screening methods: A decision analysis. Gastroenterology 2004;126:1270-9.

16. Kurahashi T, Kaneko K, Makino R, Mitamura K. Colorectal carcinoma with special reference to growth pattern classifications: Clinicopathologic characteristics and genetic changes. J Gastroenterol 2002;37:354-62.

17. Detsky AS. Screening for colon cancer - can we afford colonoscopy? N Engl J Med 2001;345:607-8. 


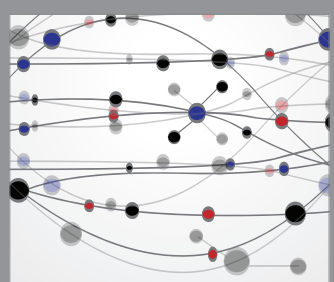

The Scientific World Journal
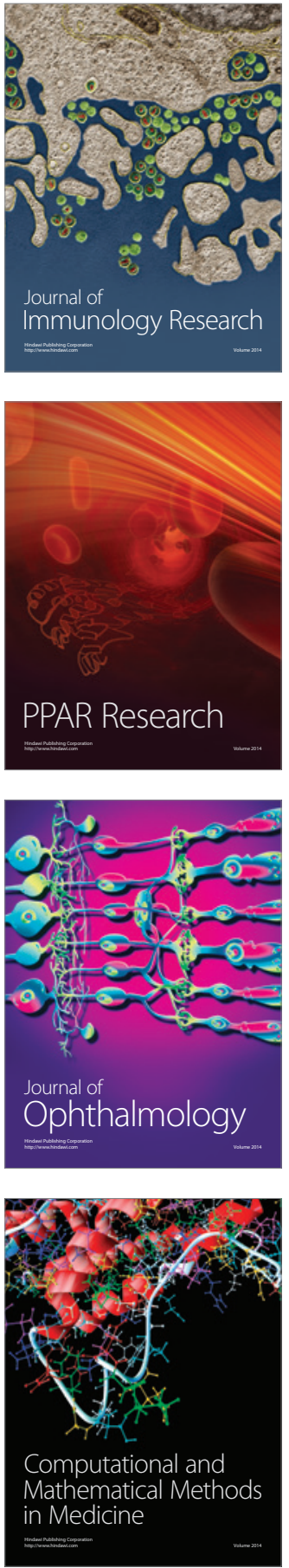

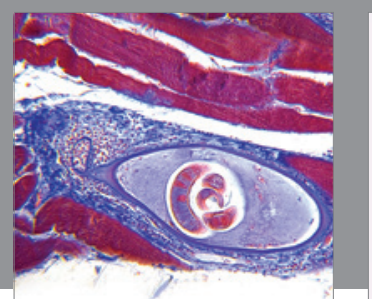

Gastroenterology Research and Practice

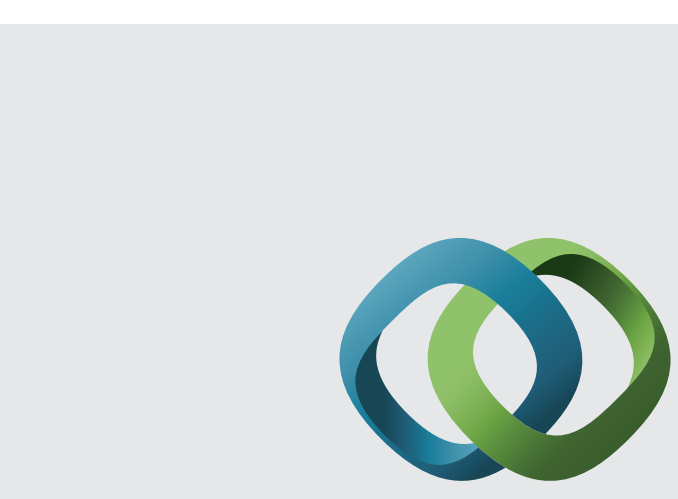

\section{Hindawi}

Submit your manuscripts at

http://www.hindawi.com
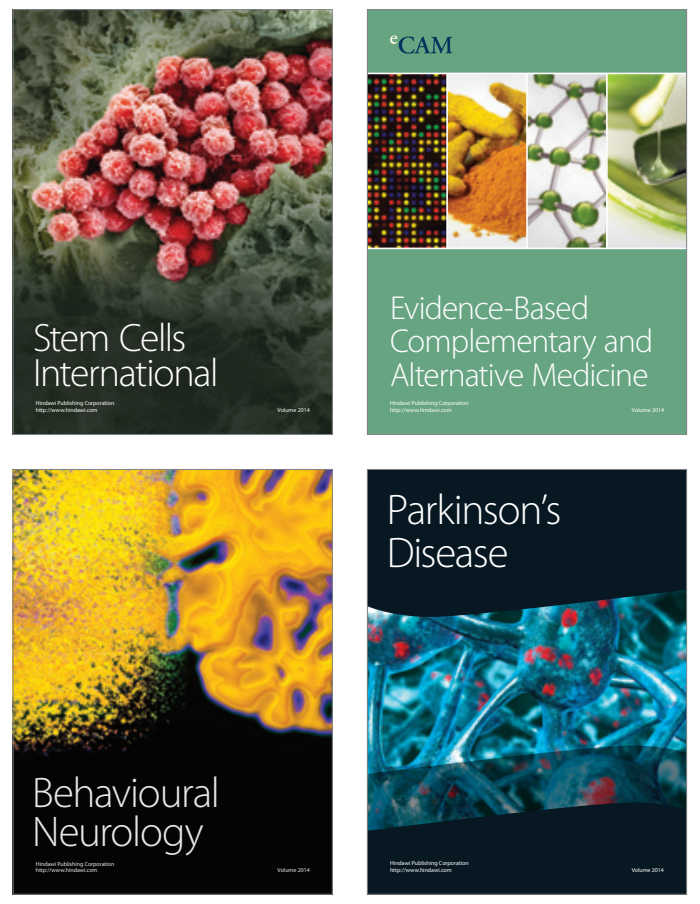
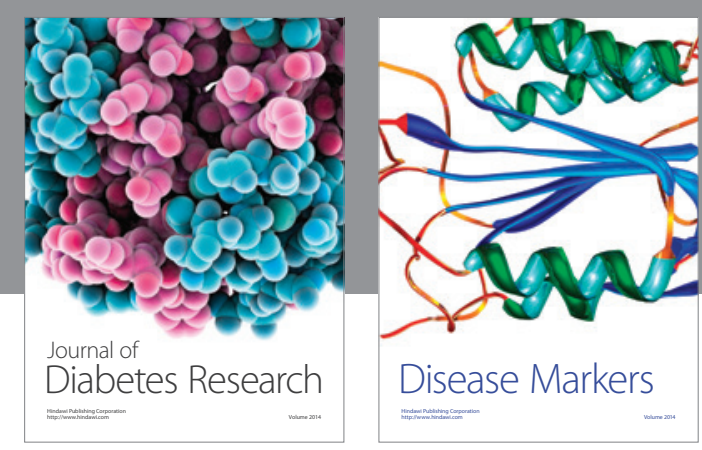

Disease Markers
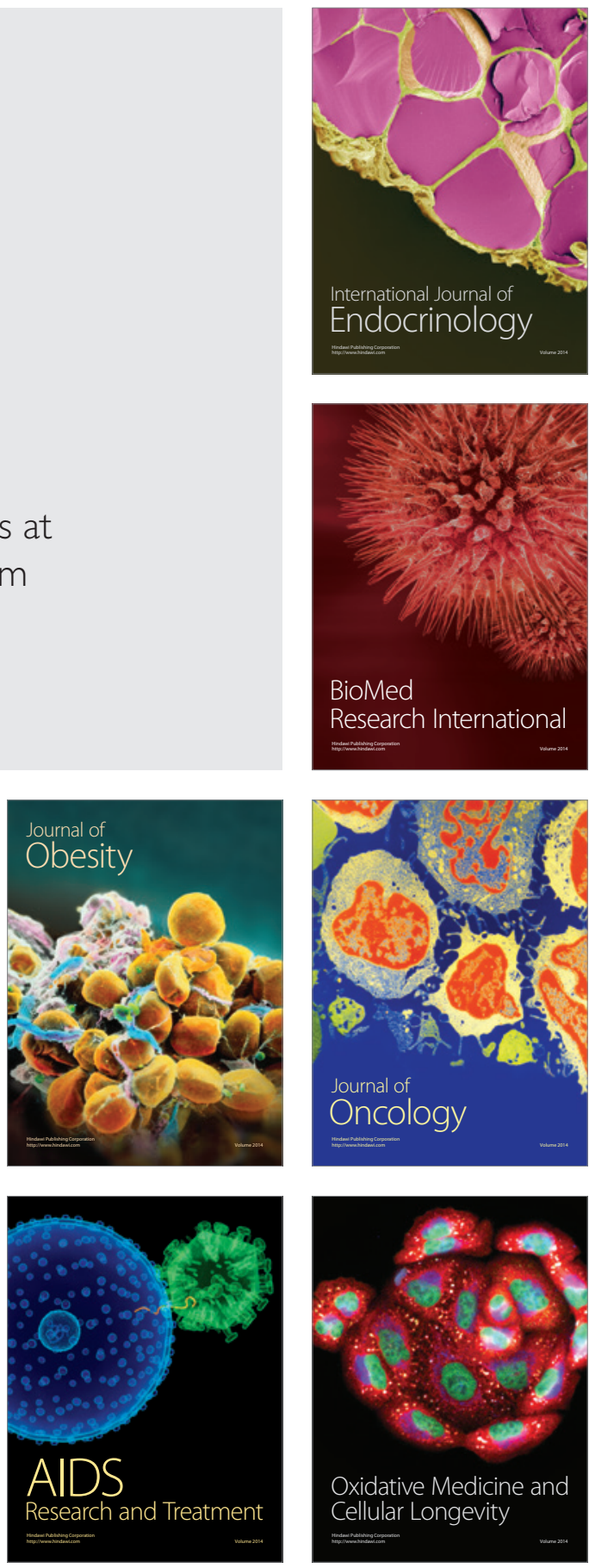